\title{
Application of Interval Valued Fuzzy Linear Programming for Stock Portfolio Optimization
}

\author{
Deyu Yin \\ Rizhao Polytechnic, Rizhao, China \\ Email: yindeyu@163.com
}

How to cite this paper: Yin, D.Y. (2018) Application of Interval Valued Fuzzy Linear Programming for Stock Portfolio Optimization. Applied Mathematics, 9, 101-113. https://doi.org/10.4236/am.2018.92007

Received: January 17, 2018

Accepted: February 20, 2018

Published: February 23, 2018

Copyright $\odot 2018$ by author and Scientific Research Publishing Inc. This work is licensed under the Creative Commons Attribution International License (CC BY 4.0).

http://creativecommons.org/licenses/by/4.0/

\begin{abstract}
In this paper, based on existing results, decision making about portfolio investment schemes is discussed, ordering method of fuzzy numbers of interval value is shown, corresponding auxiliary models are established and solutions are provided with theories of fuzzy mathematics, optimization theory and numerical calculation, etc. Then it applies software programming to solve the portfolio investment situation between investors in savings and four securities according to the established models. The result shows that investors can choose the risk coefficient that they can bear to reach the maximum value of expected returns. The greater the risk coefficient, the greater the income, the smaller the risk coefficient and the smaller the income. Investors can determine their own portfolio strategy according to their own conditions in order to meet their own interests.
\end{abstract}

\section{Keywords}

Stock Portfolio Investment, Mathematical Optimization Model, Application

\section{Introduction}

Portfolio investment is quoted securities investment, a narrow sense of investment. It refers to the behavior that an enterprise or individual buys negotiable securities such as stocks and bonds with accumulated money to earn profits. For financial institutions, it refers to businesses that take securities as the business objects, and objectives of portfolio investment are mainly issuance and purchase of government bonds, corporate bonds and stocks. Portfolio investment is mainly composed of three elements: income, risk and time. Risk refers to the uncertainty of the future income situation, that is, the possibility of making a profit and a loss. It can be summed up as system risk and non-system risk. In- 
come is value added after a period of holding a bond, equal to the ratio between the actual income in the holding period and the bond buying price. It mainly includes income profit and capital gains. Portfolio investment has the following characteristics: 1) portfolio investment is featured with a high degree of "market forces" [1] [2] [3]; 2) portfolio investment is risk investment to quoted securities expected to lead income; 3 ) investment and speculation are the two indispensable behaviors in portfolio investment; 4) portfolio investment in level-2 market will not increase total social capital, but redistribute between holders.

\section{Algorithm for Sequencing of Fuzzy Numbers of Interval Value}

\subsection{Fuzzy Theory and Method}

Professor L. A. Zadeh from California University of America published a famous paper in 1965 [4]. It is the first time to put forward the important concept of expressing fuzziness: membership function, which broke through the classical set theory of Descartes in the late 19th century and laid the foundation of fuzzy theory. It mainly includes the content of fuzzy set theory, fuzzy logic, fuzzy reasoning and fuzzy control.

Fuzzy theory is based on fuzzy set, with the basic spirit of accepting the existence of the phenomenon of fuzzy facts, and based on the research object of matters with fuzzy and uncertain concept, and actively and rigorously quantifying it into information that the computer can handle, rather than resolving the model with complex mathematical analysis, i.e. model [5] [6] [7].

\subsection{Basic Concept of Fuzzy Sets of Interval Value}

Fuzzy mathematics is a science to study and deal with fuzzy phenomenon. To resolve problems of system optimization, process control and the like in nondeterministic environment, it requires firstly mastering the basic theory of fuzzy mathematics. There the basic concept of fuzzy sets, especially the concept of fuzzy number, operation method and basic theorem, is introduced basically.

Fuzzy set of interval value is a kind of generalized fuzzy set, the mark $[I]=\{[a, b]: a \leq b, a, a \in[0,1]\}$ is introduced.

Definition 2.3.1: Set $X$ as a nonempty set (that is, set in general), called $A: X \in[I]$ as fuzzy set of interval value on section of $X$.

Attention, because of $\forall a \in[0,1], a=[a, a] \in[I]$, the fuzzy set of interval valued is generalization of fuzzy set. Generally speaking, if it is set fuzzily in an interval value, the membership degree of an element is not a number, but a small section included in $[0,1]$, so image of the fuzzy set is not a curve, but a belt area.

Definition 2.3.2: The closed interval $a=\left[a^{-}, a^{+}\right]\left(0 \leq a^{-} \leq a^{+} \leq 1\right)$ in $[0,1]$ is called as a closed interval number on $[0,1]$, and all close interval numbers on $[0,1]$ is recorded as $\bar{L}_{1}$.

$\tilde{A}$ Is a subset of fuzzy number in an interval on $X, \tilde{A}(\bullet)$ is called as subordinating degree function of $\tilde{A}$, and $\tilde{A}(x)$ is called as degree of membership of 
$x$ to fuzzy number set of interval value $\tilde{A} . \tilde{A}^{+}(x)$ and $\tilde{A}^{-}(x)$ are called as upper and lower degree of membership (membership function) respectively fuzzy set of interval value, so it is determined that the fuzzy sets $\tilde{A}^{+}$and $\tilde{A}^{-}$ are upper and lower fuzzy sets of fuzzy set of interval value $\tilde{A}$.

Entire collection of fuzzy set of interval value on $X$ is called as fuzzy power set of interval value. Exceptionally, when $\tilde{A}^{+}$and $\tilde{A}^{-}$degrade into common set, the fuzzy set of interval value turns into common set of interval value.

Lemma $\tilde{A} \subseteq \tilde{B} \Leftrightarrow \forall x \in X, \tilde{A}^{-}(x) \leq \tilde{B}^{-}(x), \tilde{A}^{+}(x) \leq \tilde{B}^{+}(x)$.

\subsection{Sequencing of Fuzzy Number of Interval Value}

1) It is assumed that $\mu_{\tilde{\alpha}}^{L}(x)$ expresses left membership function of fuzzy number $\tilde{\alpha}=(\alpha, \beta, \gamma)$, and it continues on $[\alpha, \beta]$ and decreases progressively strictly. It is assumed that $g_{\tilde{\alpha}}^{L}(y)$ and $g_{\tilde{\alpha}}^{R}(y)$ are inverse functions on $\mu_{\tilde{\alpha}}^{L}(x)$ and $\mu_{\tilde{\alpha}}^{R}(x)$ respectively, it is obvious that they continue on $[0,1]$, and increases and decreases progressively strictly. Therefore, $g_{\tilde{\alpha}}^{L}(y)$ and $g_{\tilde{\alpha}}^{R}(y)$ are integrable respectively in interval $[0,1]$, recorded as follows:

$$
I_{L}(\tilde{\alpha})=\int_{0}^{1} g_{\tilde{\alpha}}^{L}(y) \mathrm{d} y, I_{R}(\tilde{\alpha})=\int_{0}^{1} g_{\tilde{\alpha}}^{R}(y) \mathrm{d} y
$$

Definition 2.3.1: If $\tilde{\alpha}$ is a fuzzy number, and the membership function definition is shown in (1), $I_{T}(\tilde{\alpha})$ is called as the entire expected value of the fuzzy number. Including

$$
I_{T}(\tilde{\alpha})=\frac{I_{L}(\tilde{\alpha})+I_{R}(\tilde{\alpha})}{2}
$$

According to above definition:

i) For $\tilde{\alpha}=(\alpha, \beta, \gamma)$, there is $I_{T}(\tilde{\alpha})=\frac{\alpha+\gamma+2 \beta}{4}$.

In this way, if $\tilde{r}_{i}=\left(r_{i 1}, r_{i 2}, r_{i 3}\right), I_{T}\left(\tilde{r}_{i}\right)=\frac{r_{i 1}+r_{i 3}+2 r_{i 2}}{4}$.

ii) As for the sum of $n$ triangle fuzzy numbers $\tilde{\alpha}_{1}, \tilde{\alpha}_{2}, \cdots, \tilde{\alpha}_{n}$, there is:

$$
I_{T}\left(\sum_{i=1}^{n} \tilde{\alpha}_{i}\right)=\sum_{i=1}^{n} I_{T}\left(\tilde{\alpha}_{i}\right)
$$

2) Definition 2.3.2: It is assumed that $A=\left[A^{-}, A^{+}\right]$is a fuzzy set of interval value on $R$ and $A^{-}$and $A^{+}$are closed fuzzy numbers on $R$, and then $A$ is a fuzzy number of closed interval value. The collection of all fuzzy numbers of closed interval values are recorded as $E$.

Definition 2.3.3: It is assumed that $A \in E$ and $A=\left[A^{-}, A^{+}\right]$. If $A^{-}$and $A^{+}$are triangle fuzzy numbers, and then $A$ is a fuzzy number in a triangle interval value. The collection of all fuzzy numbers of triangle interval values is recorded as $I F N$.

Theorem: It is assumed that $A=\left[A^{-}, A^{+}\right], B=\left[B^{-}, B^{+}\right]$are fuzzy numbers in two triangle interval values:

$$
A^{-}=\left(a_{0}^{-}, a_{1}^{-}, a_{2}^{-}\right), A^{+}=\left(a_{0}^{+}, a_{1}^{+}, a_{2}^{+}\right), B^{-}=\left(b_{0}^{-}, b_{1}^{-}, b_{2}^{-}\right), B^{+}=\left(b_{0}^{+}, b_{1}^{+}, b_{2}^{+}\right),
$$


So $\forall k \in R^{+}, \quad A+B=\left[A^{-}+B^{-}, A^{+}+B^{+}\right]$,

$$
\begin{gathered}
A-B=\left[A^{-}-B^{-}, A^{+}-B^{+}\right], \\
k A=\left[k A^{-}, k A^{+}\right](k \geq 0), k A=\left[k A^{+}, k A^{-}\right](k \prec 0) .
\end{gathered}
$$

Wherein $A^{-} \pm B^{-}=\left(a_{0}^{-} \pm b_{0}^{-}, a_{1}^{-} \pm b_{1}^{-}, a_{2}^{-} \pm b_{2}^{-}\right)$

$$
\begin{gathered}
A^{+} \pm B^{+}=\left(a_{0}^{+} \pm b_{0}^{+}, a_{1}^{+} \pm b_{1}^{+}, a_{2}^{+} \pm b_{2}^{+}\right), \\
k A^{-}=\left(k a_{0}^{-}, k a_{1}^{-}, k a_{2}^{-}\right), k A^{+}=\left(k a_{0}^{+}, k a_{1}^{+}, k a_{2}^{+}\right) .
\end{gathered}
$$

As for triangle fuzzy numbers $a=\left(a_{0}, a_{1}, a_{2}\right)$ and $b=\left(b_{0}, b_{1}, b_{2}\right)$, we apply the following two fuzzy order relations $a \leq b \Leftrightarrow a_{2} \leq b_{1}$ and $a \leq b \Leftrightarrow a_{0}+a_{1}+a_{2} \leq b_{0}+b_{1}+b_{2}$.

It is assumed $A=\left[A^{-}, A^{+}\right], B=\left[B^{-}, B^{+}\right]$are fuzzy numbers of two triangle interval values and

$A^{-}=\left(a_{0}^{-}, a_{1}^{-}, a_{2}^{-}\right), A^{+}=\left(a_{0}^{+}, a_{1}^{+}, a_{2}^{+}\right), B^{-}=\left(b_{0}^{-}, b_{1}^{-}, b_{2}^{-}\right), B^{+}=\left(b_{0}^{+}, b_{1}^{+}, b_{2}^{+}\right)$.

The sequencing method of fuzzy numbers of triangle interval values are shown as below:

1) $A \leq B \Leftrightarrow a_{2}^{-} \leq b_{1}^{-}, a_{2}^{+} \leq b_{1}^{+}$;

2) $A \leq B \Leftrightarrow a_{0}^{-}+a_{1}^{-}+a_{2}^{-} \leq b_{0}^{-}+b_{1}^{-}+b_{2}^{-}, a_{0}^{+}+a_{1}^{+}+a_{2}^{+} \leq b_{0}^{+}+b_{1}^{+}+b_{2}^{+}$.

\section{Stock Portfolio Investment Model Based on Fuzzy Linear Programming of Interval Value}

\subsection{Linear Programming}

Linear programming is an important branch of operational research, which has been studied earlier, developed rapidly, used widely and matured. It is a mathematical method to assist people in scientific management. In the management activities of enterprises, such as planning, production, transportation, technology and other issues, linear programming refers to the process of selecting the most reasonable calculation method from various restrict combinations, establishing a linear programming model to obtain the best results [8]. The basic method to solve the linear programming problem is simple method. The standard software of existing simplex method is available to linear programming problem with more than 10,000 of constraint conditions and decision variables on computer. To improve the speed of solving problems, improved simplex method, original duality method, decomposition algorithm and various polynomial time algorithms are available.

1) Fuzzy linear programming

Fuzzy set theory developed in 1950s and fuzzy optimization method based on the theory provide effective methods and techniques for modeling and optimizing this kind of soft system. The study of fuzzy optimization theory and method originated from the concept of fuzzy decision made by Bellman and Zadeh in 1970s and the decision model under the fuzzy environment. Many scholars have studied fuzzy linear programming model, fuzzy multi-objective programming 
model, fuzzy integer programming model, fuzzy dynamic programming model, possible linear partitioning model and fuzzy nonlinear programming model, and given methods knowing such models. At the same time, application of fuzzy sequencing, fuzzy set operation, sensitivity analysis, duality theory and fuzzy optimization in production practice also become important research contents of fuzzy optimization theory and method [9].

2) Interval number linear programming

The objective discussed by interval number linear programming problem, as a flexible mathematical programming, is that the value of the target coefficient is a closed interval, or the restraint coefficient and objective function coefficients are interval numbers. Then according to the maximum inequality in equation and the minimum in equation, the possible interval of the objective function solution is obtained, so as to translate interval number linear programming into classical multi-objective linear programming problem, and find an effective solution or the effective solution interval. Similarly, when the objective function constraint conditions are all interval numbers, we can use the ordinal relation of interval numbers to measure the degree of variables to constraint conditions, so as to gets any effective solution of interval number linear programming. With the method, the decision maker can get the expected effective solution according to estimated value of optimization level of satisfaction level to objective function and constraint conditions.

3) Fuzzy linear programming of interval numbers

During decision-making, evaluation and other applications, because of the lack of understanding in nature of the development, people often use interval numbers to express the decision attributes, so as to reduce the uncertainty of decision-making. Since the theory of fuzzy set was put forward, scholars began to carry out a series of researches in this direction, applying fuzzy set theory to reasoning, signal transmission and fuzzy control, etc. [10]. In practical application, it is often not easy to determine the membership function of a fuzzy set, but it is relatively easy to determine the membership degree of the interval value. Therefore, it provides a new way for sequencing of fuzzy numbers of interval value, which gets the common model of interval valued fuzzy linear programming problem, and then solves corresponding problems.

\subsection{Establishment of Interval Value Fuzzy Linear Programming Model for Stock Portfolio Investment}

In reality, since the investment environment is quite complex, certain small changes will affect the choice of portfolio. In this case, in order to facilitate in discussing problems, the model assumes that:

1) Investors evaluate the securities by the expected rate of return and the risk loss rate;

2) Securities are indefinite and can be divided;

3) There is no need to pay the transaction costs in the course of transaction; 
4) Investors obey the assumption of non-satisfaction and assumption of avoiding risk;

5) Short selling operation is not allowed;

6) Interest rate of the bank is unchanged for the investors during the investment period.

It is supposed that investors (or asset managers) invest in $n$ risk securities. $r_{i}, A(i=1,2, \cdots, n)$ is expected return rate and rate of risked return respectively, $r_{0}$ is interest rate of the bank, $x_{i}(i=1,2, \cdots, n)$ is the proportion of funds invested in the secondary securities, $x_{0}$ is the proportion of the total amount of investment in the investment period. $n+1$ vector quantity: $X=\left(x_{0}, x_{1}, x_{2}, \cdots, x_{n}\right)$ is the expected return rate of an investment combination held by the investors, shown as follows:

$$
R=r_{0} x_{0}+\sum_{i=1}^{n} r_{i} x_{i} .
$$

If investors are rational, investors will pursue maximization of investment interest and expect the minimum risk of investment after buying some risk securities. If $b$ is assumed as the risk coefficient of portfolio investment, $A$ is risk coefficient of $i$ securities. Coefficient $b$ reflects market risk of portfolio investment. When $\beta>1$, risk of stock portfolio is greater than the average market risk; when $b=1$, risk of stock portfolio is equal to the average market risk; when $b<1$, the risk of stock portfolio is less than the average market risk, in which case, the risk of combination $X$ is defined as the maximum value of various securities risks, namely

$$
V=\max \left(a_{1} x_{1}, a_{2} x_{2}, \cdots, a_{n} x_{n}\right)
$$

So we can find the effective combination according to the sum of the securities risk in the portfolio not more than a given level, and the maximum expected return rate of the combination. Its linear programming model is as follows:

$$
\begin{aligned}
& \max R=r_{0} x_{0}+\sum_{i=1}^{n} r_{i} x_{i} \\
& P_{1} \text { :s.t. }\left\{\begin{array}{l}
A x \leq b \\
x_{0}+\sum_{i=1}^{n} x_{i}=1 \\
x_{x} \geq 0(i=0,1,2, \cdots, n)
\end{array}\right.
\end{aligned}
$$

Wherein, $b$ is the portfolio risk amount that the investor is willing to bear, and it is the risk parameter given by the investor. When $r_{i}, A(i=1,2, \cdots, n)$ is a determined parameter, the above model is a common linear programming problem. For the flexible consideration of income and risk, it is more reasonable to use the fuzzy number to describe $r_{i}, A$ and $b$. In this paper, $r_{i}$ is equipped with triangular fuzzy number and $A, b$ is equipped with triangular interval value fuzzy number, generally recorded as:

$\tilde{r}_{i}=\left(r_{i 1}, r_{i 2}, r_{i 3}\right), A=\left(A^{-}, A^{+}\right), b=\left(b^{-}, b^{+}\right)$, wherein, $r_{i 1} \leq r_{i 2} \leq r_{i 3}$, and its membership function is: 


$$
\mu_{\gamma_{i}}(x)= \begin{cases}0 & x \prec \gamma_{i 1} \\ \frac{x-\gamma_{i 1}}{\gamma_{i 2}-\gamma_{i 1}} & \gamma_{i 1} \leq x \prec \gamma_{i 2} \\ \frac{\gamma_{i 3}-x}{\gamma_{i 3}-\gamma_{i 2}} & \gamma_{i 2} \leq x \prec \gamma_{i 3} \\ 0 & x \succ \gamma_{i 3}\end{cases}
$$

Wherein, $x$ in $\mu_{\gamma_{i}}(x)$ is the variable of expected return rate, and the membership $\mu_{\gamma_{i}}(x)$ reflects the credibility of the expected return rate of $x$ as the $i^{\text {th }}$ security. When $x=\gamma_{i 2}$, membership $\mu_{\gamma_{\mathrm{i}}}(x)=1$, the credibility of expected return rate of $\gamma_{i 2}$ as the $i^{\text {th }}$ security dominates; when value of $x$ is near $\gamma_{i 2}$ and expanded left and right, the membership $\mu_{\gamma_{i}}(x)$ decreased gradually, that is, corresponding credibility gradually decreased; when $x \prec \gamma_{i 1}$ or $x \succ \gamma_{i 3}$, the membership $\mu_{\gamma_{i}}(x)=0$, that is, it is incredible when the expected return rate of $i^{\text {th }}$ security is less than $\gamma_{i 1}$ or more than $\gamma_{i 3}$.

Finally, translate above linear programming model $P_{1}$ into $P_{2}$ :

$$
\begin{aligned}
& \max \tilde{R}=r_{0} x_{0}+\sum_{i=1}^{n} \tilde{r}_{i} x_{i} \\
& P_{2} \text { s.t. }\left\{\begin{array}{l}
\tilde{A} x \leq \tilde{b} \\
x_{0}+\sum_{i=1}^{n} x_{i}=1 \\
x_{x} \geq 0(i=0,1,2, \cdots, n)
\end{array}\right.
\end{aligned}
$$

\subsection{Solution of Fuzzy Linear Programming Model of Portfolio Investment Interval Value}

Definition 3.3.1: It is assumed that $A=\left(a_{i j}\right)_{m \times n}, \quad b=\left(b_{1}, b_{2}, \cdots, b_{m}\right)^{\mathrm{T}}$, $r=\left(r_{1}, r_{2}, \cdots, r_{n}\right)$,

$x=\left(x_{1}, x_{2}, \cdots, x_{n}\right)^{\mathrm{T}}$, where in, $a_{i j}, b_{i} \in I F N$,

$r_{j}, x_{j} \in R(i=1,2, \cdots, m ; j=1,2, \cdots, n)$,

$\max \tilde{R}=r_{0} x_{0}+\tilde{r} x_{i}$

Then $\left\{\begin{array}{l}A x \leq b \\ x_{0}+\sum_{i=1}^{n} x_{i}=1 \\ x_{x} \geq 0(i=0,1,2, \cdots, n)\end{array}\right.$

Called as fuzzy linear programming of interval.

Algorithm of the solution (4.1) is shown as following:

Step 1: translate (4.1) into (4.2)

$$
\begin{aligned}
& \max \tilde{R}=r_{0} x_{0}+\sum_{i=1}^{n} \tilde{r}_{j} x_{j} \\
& \text { s.t. } \begin{cases}\sum_{j=1}^{n} a_{i j} x_{j} \leq b_{j} & i=1,2, \cdots m \\
x_{0}+\sum_{i=1}^{n} x_{i}=1 & \\
x_{j} \geq 0 & j=1,2, \cdots, n\end{cases}
\end{aligned}
$$


Step 2: It is assumed that $a_{i j}=\left(a_{i j}^{-}, a_{i j}^{+}\right), b_{i j}=\left(b_{i j}^{-}, b_{i j}^{+}\right)$and $a_{i j}^{-}=\left(a_{i j 0}^{-}, a_{i j 1}^{-}, a_{i j 2}^{-}\right)$, $a_{i j}^{+}=\left(a_{i j 0}^{+}, a_{i j 1}^{+}, a_{i j 2}^{+}\right), \quad b_{i j}^{-}=\left(b_{i j 0}^{-}, b_{i j 1}^{-}, b_{i j 2}^{-}\right), \quad b_{i j}^{+}=\left(b_{i j 0}^{+}, b_{i j 1}^{+}, b_{i j 2}^{+}\right)$. In Equation (3.2), two linear programming problems can be gotten based on the result of the theorem:

$$
\begin{aligned}
& \max \tilde{R}=r_{0} x_{0}+\sum_{j=1}^{n} \frac{r_{j 1}+r_{j 3}+2 r_{j 2}}{4} x_{j} \\
& \text { s.t. } \begin{cases}\sum_{j=1}^{n} a_{i j}^{-} x_{j} \leq b_{j}^{-} \\
\sum_{j=1}^{n} a_{i j}^{+} x_{j} \leq b_{j}^{+} & i=1,2, \cdots, m \\
x_{0}+\sum_{i=1}^{n} x_{i}=1 & \\
x_{j} \geq 0 & j=1,2, \cdots, n\end{cases}
\end{aligned}
$$

And

$$
\begin{aligned}
& \max \tilde{R}=r_{0} x_{0}+\sum_{j=1}^{n} \frac{r_{j 1}+r_{j 3}+2 r_{j 2}}{4} x_{j} \\
& \int\left[\sum_{j=1}^{n} a_{i j 0}^{-} x_{j}, \sum_{j=1}^{n} a_{i j 1}^{-} x_{j}, \sum_{j=1}^{n} a_{i j 2}^{-} x_{j}\right] \leq\left(b_{i 0}^{-}, b_{i 1}^{-}, b_{i 2}^{-}\right) \\
& \text {s.t. }\left\{\left[\sum_{j=1}^{n} a_{i j 0}^{+} x_{j}, \sum_{j=1}^{n} a_{i j 1}^{+} x_{j}, \sum_{j=1}^{n} a_{i j 2}^{+} x_{j}\right] \leq\left(b_{i 0}^{+}, b_{i 1}^{+}, b_{i 2}^{+}\right)\right. \\
& \begin{array}{l}
x_{0}+\sum_{i=1}^{n} x_{i}=1 \\
x_{j} \geq 0
\end{array} \\
& i=1,2, \cdots, m ; j=1,2, \cdots, n
\end{aligned}
$$

Step 3: two auxiliary models of (i) and (ii) can be gotten:

$$
\begin{aligned}
& \max \tilde{R}=r_{0} x_{0}+\sum_{j=1}^{n} \frac{r_{j 1}+r_{j 3}+2 r_{j 2}}{4} x_{j} \\
& \text { s.t. }\left\{\begin{array}{l}
\sum_{j=1}^{n} a_{i j 2}^{-} x_{j} \leq b_{i 1}^{-} \\
\sum_{j=1}^{n} a_{i j 2}^{+} x_{j} \leq b_{i 1}^{+} \\
x_{0}+\sum_{i=1}^{n} x_{i}=1 \\
x_{j} \geq 0 \quad i=1,2, \cdots, m ; j=1,2, \cdots, n
\end{array}\right.
\end{aligned}
$$

And

$$
\begin{aligned}
& \max \tilde{R}=r_{0} x_{0}+\sum_{j=1}^{n} \frac{r_{j 1}+r_{j 3}+2 r_{j 2}}{4} x_{j} \\
& \text { s.t. }\left\{\begin{array}{l}
\sum_{j=1}^{n}\left(a_{i j 0}^{-}+a_{i j 1}^{-}+a_{i j 2}^{-}\right) x_{j} \leq\left(b_{i 0}^{-}+b_{i 1}^{-}+b_{i 2}^{-}\right) \\
j=1 \\
\left.x_{0}+\sum_{i=1}^{n} x_{i}^{+}+a_{i j 1}^{+}+a_{i j 2}^{+}\right) x_{j} \leq\left(b_{i 0}^{+}+b_{i 1}^{+}+b_{i 2}^{+}\right) \\
x_{j} \geq 0 \quad i=1,2, \cdots, m ; j=1,2, \cdots, n
\end{array}\right.
\end{aligned}
$$


Step 4: resolve with formula (3.5) and form (3.6) with Lingo software or simplex method, then the best solution of the formula (3.5) and form (3.6) can be gotten. According to the above analysis, we can think that the optimal solution is the optimal solution of formula 3.1.

\section{Analysis of Examples}

The petrochemical industry that is one of the pillar industries in our country plays a vital role in the development of the national economy. In recent years, frequent fluctuations are in oil prices, a large number of funds are invested in the petroleum chemical industry, oil prices may be regulated upward within this year, the stock market reaction is fierce; in recent years, the housing price keeps high, and even produces large changes in the price in one day. The real estate market is very active, occupying a certain proportion in the China GDP. Its importance is self-evident. Therefore, it is of great significance to analyze the investment in China's petrochemical and real estate securities markets.

In view of this, this paper selects the following 4 kinds of stocks:

$S_{1}$ CNPC (601857):the largest dominated oil and gas producer and distributor in China's oil and gas industry, one of companies the largest sales incomes in China, and one of the largest oil companies in the world, one of the largest state-owned enterprise groups in China.

$\mathrm{S}_{2}$ CNPC (600028): one of the largest integrated energy and chemical companies in China, also China's largest producer and supplier of petroleum products and main petrochemical products, and also China's second largest producer of crude oil.

$\mathrm{S}_{3}$ Wanke A (000002): At present, the largest professional residential development enterprise in China, also the representative real estate blue chip stock in the stock market.

$\mathrm{S}_{4}$ Poly Real Estate (600048): The large state-owned real estate enterprise, the operation platform of the real estate business of China Poly Group and the national first class real estate development qualification enterprise.

To sum up, the above 4 kinds of stocks have great influence in their industry and are representative in the petroleum real estate stock. So we take this as a reference to demonstrate the validity and reliability of the above models.

\subsection{Data Preparation}

The above 4 securities are selected and the following data are obtained on the basis of the annual financial reports of the companies in 2009. We consider the choice of an investor (an individual or enterprise) in the portfolio of bank savings and the 4 stocks. The data of the expected return rate and the risk loss rate of the 4 stocks are listed as follows (Table 1, Table 2).

As For an investor (an individual or enterprise), if we assume the annual bank interest rate of current period is $r_{0}=0.07$, the risk coefficient is as follows (Table 3). 
Table 1. Expected return rate \%.

\begin{tabular}{ccccc}
\hline $\begin{array}{c}\mathrm{S}_{1} \text { CNPC } \\
(601857)\end{array}$ & $\begin{array}{c}\mathrm{S}_{2} \text { CNPC } \\
(600028)\end{array}$ & $\begin{array}{c}\mathrm{S}_{3} \text { Wanke A } \\
(000002)\end{array}$ & $\begin{array}{c}\mathrm{S}_{4} \text { Poly Real Estate } \\
(600048)\end{array}$ \\
\hline$\tilde{r}_{i}$ & $(11.5,12.2,12.9)$ & $(15.8,16.3,16.8)$ & $(13.7,14.3,14.9)$ & $(13.0,14.0,15.0)$ \\
\hline
\end{tabular}

Table 2. Risk loss rate $\%$.

\begin{tabular}{|c|c|c|c|}
\hline \multicolumn{2}{|c|}{$A_{11}$} & \multicolumn{2}{|c|}{$A_{12}$} \\
\hline- & + & - & + \\
\hline$(3.8,5.2,5.9)$ & $(6.3,9.0,11.6)$ & $(9.0,12.5,16.9)$ & $(17.2,18.7,20.0)$ \\
\hline \multicolumn{2}{|c|}{$A_{13}$} & \multicolumn{2}{|c|}{$A_{14}$} \\
\hline- & + & - & + \\
\hline$(3.2,4.8,6.0)$ & $(7.1,9.9,11.0)$ & $(8.7,11.9,16.3)$ & $(14.1,19.0,23.0)$ \\
\hline \multicolumn{2}{|c|}{$A_{21}$} & \multicolumn{2}{|c|}{$A_{22}$} \\
\hline- & + & - & + \\
\hline$(1.1,0.9,1.31)$ & $(2.15,3.32,1.39)$ & $(1.1,0.9,1.31)$ & $(2.15,3.32,1.39)$ \\
\hline \multicolumn{2}{|c|}{$A_{23}$} & \multicolumn{2}{|c|}{$A_{24}$} \\
\hline- & + & - & + \\
\hline$(1.2,4.8,3.26)$ & $(7.12,1.59,2.27)$ & $(1.2,4.8,3.26)$ & $(7.12,1.59,2.27)$ \\
\hline
\end{tabular}

Table 3. Risk coefficient \%.

\begin{tabular}{ccccc}
\hline & $b_{1}$ & & \multicolumn{3}{c}{$b_{2}$} \\
\hline- & & + & - & + \\
$(2.0,1.2,2.4)$ & & $(1.5,1.9,2.9)$ & $(0.6,0.4,3.0)$ & $(2.7,1.4,1.1)$ \\
\hline
\end{tabular}

\subsection{Numerical Example Solution}

Now we consider how to determine the proportion of investment between savings and the 4 stocks, and make the correct portfolio investment, so that the expected return will reach the maximum value [5] [7] when the existing risk loss rate and the risk coefficient are acceptable.

It is known from the analysis of the Chapter 4 that the following mathematical models are established firstly.

$$
\begin{aligned}
& \max \tilde{R}=r_{0} x_{0}+\sum_{j=1}^{n} \frac{1}{4}\left(r_{j 1}+r_{j 3}+2 r_{j 2}\right) x_{j} \\
& \text { s.t. }\left\{\begin{array}{l}
A_{11} x_{1}+A_{12} x_{2}+A_{13} x_{3}+A_{14} x_{4} \leq b_{1} \\
A_{21} x_{1}+A_{22} x_{2}+A_{23} x_{3}+A_{24} x_{4} \leq b_{2} \\
x_{0}+x_{1}+x_{2}+x_{3}+x_{4}=1 \\
x_{j} \geq 0, i=0,1,2,3,4
\end{array}\right.
\end{aligned}
$$

According to formula (3.5) gained based on fuzzy number sequencing of interval value, translate the formula (4.1) into the following auxiliary model: 


$$
\begin{aligned}
& \max \tilde{R}=0.07 x_{0}+0.122 x_{1}+0.163 x_{2}+0.143 x_{3}+0.14 x_{4} \\
& \text { s.t. }\left\{\begin{array}{l}
0.059 x_{1}+0.169 x_{2}+0.06 x_{3}+0.163 x_{4} \leq 0.012 \\
0.0131 x_{1}+0.026 x_{2}+0.0326 x_{3}+0.216 x_{4} \leq 0.004 \\
0.116 x_{1}+0.2 x_{2}+0.11 x_{3}+0.23 x_{4} \leq 0.019 \\
0.0139 x_{1}+0.032 x_{2}+0.0227 x_{3}+0.3243 x_{4} \leq 0.014 \\
x_{0}+x_{1}+x_{2}+x_{3}+x_{4}=1 \\
x_{j} \geq 0, i=0,1,2,3,4
\end{array}\right.
\end{aligned}
$$

It is known what is the optimal solution of the above linear programming with Lingo software:

$$
x^{*}=\left(x_{0}^{*}, x_{1}^{*}, x_{2}^{*}, x_{3}^{*}, x_{4}^{*}\right)=(0.8315,0.0766,0,0.0919,0) ;
$$

The optimal value is $R^{*}=0.0807$.

Then, according to formula (3.6), translate the formula (4.1) into the following auxiliary model:

$$
\begin{aligned}
& \max \tilde{R}=0.07 x_{0}+0.122 x_{1}+0.163 x_{2}+0.143 x_{3}+0.14 x_{4} \\
& \text { s.t. }\left\{\begin{array}{l}
0.149 x_{1}+0.384 x_{2}+0.14 x_{3}+0.369 x_{4} \leq 0.056 \\
0.0331 x_{1}+0.048 x_{2}+0.0926 x_{3}+0.352 x_{4} \leq 0.04 \\
0.269 x_{1}+0.559 x_{2}+0.28 x_{3}+0.561 x_{4} \leq 0.063 \\
0.0686 x_{1}+0.0507 x_{2}+0.1098 x_{3}+0.5779 x_{4} \leq 0.052 \\
x_{0}+x_{1}+x_{2}+x_{3}+x_{4}=1 \\
x_{j} \geq 0, i=0,1,2,3,4
\end{array}\right.
\end{aligned}
$$

It is known what is the optimal solution of above linear programming with Lingo software:

$$
x^{*}=\left(x_{0}^{*}, x_{1}^{*}, x_{2}^{*}, x_{3}^{*}, x_{4}^{*}\right)=(0.775,0,0,0.225,0)
$$

The optimal value is $R^{*}=0.0864$.

\subsection{In Summary}

To sum up, the resolution is as follows (Table 4).

For the formula (4.2), when the bank interest rate is 0.07 , the securities portfolio investment strategy chosen shall be like this: $83.15 \%$ of all capital is saved into the bank, $7.66 \%$ of all capital is invested into security of $\mathrm{S}_{1} \mathrm{CNPC}, 9.19 \%$ is invested into security of $\mathrm{S}_{3}$ Wanke $\mathrm{A}$, so obtain the maximum expected return $8.07 \%$ on the premise of bearing risk coefficient $b_{1}$ and $b_{2}$.

In the same way, for the formula (4.3), when the bank interest rate is 0.07 , the securities portfolio investment strategy chosen shall be like this: $77.5 \%$ of all capital is saved into the bank, $22.5 \%$ of all capital is invested into security of $\mathrm{S}_{3}$

Table 4. Income and investment portfolio.

\begin{tabular}{cc}
\hline Income & Investment Portfolio \\
\hline 0.0807 & $(0.8315,0.0766,0,0.0919,0)$ \\
0.0864 & $(0.775,0,0,0.225,0)$ \\
\hline
\end{tabular}


Wanke A, so obtain the maximum expected return $8.64 \%$ on the premise of no purchasing any risk security and bearing risk coefficient $b_{1}$ and $b_{2}$.

It shows that when the risk coefficient that can be borne by investors' change, the expected return is variable keeps changed on premise of fuzzy expected return rate and risk loss rate. That is to say, investors can choose the risk coefficient that they can bear to reach the maximum value of the expected income.

Of course, such judgment is not blind. We can see that when the interval value of $b$ is large, the combined income is also large, so the portfolio risk is larger. When the interval value of $b$ is small, the combined risk and portfolio risk are relatively small. That is, the greater the risk coefficient, the greater the income, the smaller the risk coefficient and the smaller the income. Investors can determine their own portfolios according to their own conditions in order to meet their own interests [11].

\section{Conclusions}

In this paper, we focus on fuzzy linear programming, interval number linear programming and interval valued fuzzy linear programming based on computational mathematics, such as model analysis, algorithm analysis and numerical calculation. The main contents are as follows:

1) By using the definition and operation rules of fuzzy numbers of interval value, we find out the sequencing problem of fuzzy numbers of interval value, and apply it to the establishment of interval valued fuzzy linear programming model.

2) As for $r_{i}$, we select triangular fuzzy number and as for $A, b$, we select the triangular interval value fuzzy number, and establish portfolio investment optimization model. According to the algorithm of solving the fuzzy linear programming model of interval value, we translate it into a common linear programming model.

3) We collect specific data materials of expected return rate, etc. of 4 representative securities in petrochemical engineering and real estate industry, according to the established model, resolve the portfolio investment conditions of investors between savings and the 4 kinds of securities with software programming, and verify reliability and validity of the model.

The result shows that due to uncertainty in various correlation coefficients in securities investment, it makes investment portfolio more flexible, more close to reality and more practice to describe expected return rate, risk loss rate, affordable risk coefficient and other factors influencing investment effect, which plays a good guiding role for institutional organizations or individual investors.

\section{References}

[1] Zhang, S. (2007) Application of Modern Portfolio Theory in Chinese Securities Market. Financial Times, 6, 26-28.

[2] Liu, T.T. and Wang, L. (2009) Research on Application of Stock Portfolio Theory. Modern Business Trade Industry, 21, 139-140. 
[3] Markowitz, H.M. (1959) Portfolio Selection: Efficient Diversification of Investments. Yale University Press, Wiley.

[4] Markowitz, H.M. (1991) Foundations of Portfolio Theory. The Journal of Finance, No. 2, 469-477. https://doi.org/10.1111/j.1540-6261.1991.tb02669.x

[5] Chen, L., Peng, J., Zhang, B. and Rosyida, I. (2017) Diversified Models for Portfolio Selection Based on Uncertain Semivariance. International Journal of Systems Science, 48, 637-648. https://doi.org/10.1080/00207721.2016.1206985

[6] Qin, Z.F., KarHai, S. and Zheng, T. (2016) Uncertain Portfolio Adjusting Model Using Semiabsolute Deviation. Soft Computing, 20, 717-725. https://doi.org/10.1007/s00500-014-1535-y

[7] Zhang, B., Peng, J. and Li, S.G. (2015) Uncertain Programming Models for Portfolio Selection with Uncertain Returns. International Journal of Systems Science, 46, 2510-2519. https://doi.org/10.1080/00207721.2013.871366

[8] Zhang, Y.Y., Li, X. and Guo, S.N. (2017) Portfolio Selection Problems with Markowitz's Mean-Variance Framework: A Review of Literature. Fuzzy Optimization and Decision Making, 1-34.

[9] Liu, Y.-J. and Zhang, W.-G. (2017) Fuzzy Portfolio Selection Model with Real Features and Different Decision Behaviors. Fuzzy Optimization and Decision Making, $1-20$.

[10] Zhou, R.X., Yang, Z.B., Yu, M. and Ralescu, D.A. (2015) A Portfolio Optimization Model Based on Information Entropy and Fuzzy Time Series. Fuzzy Optimization and Decision Making, 14, 381-397. https://doi.org/10.1007/s10700-015-9206-8

[11] Wang, J., Lan, Y.F., Zhao, R.Q. and Xing, T.T. (2017) The Optimal Payment Policy for a Firm: Cash Sale versus Credit Sale. Soft Computing, 1-18. 